Research Article

\title{
Evaluation of Rheological Parameters of Slag-Based Paste Backfill with Superplasticizer
}

\author{
Zhonghui Zhang, ${ }^{1,2}$ Yuanhui Li, ${ }^{1}$ Lei Ren, ${ }^{1}$ Zhenbang Guo ${ }^{D},{ }^{1}$ Haiqiang Jiang, ${ }^{1}$ and Na Liu ${ }^{3}$ \\ ${ }^{1}$ Key Laboratory of Ministry of Education on Safe Mining of Deep Metal Mines, Northeastern University, Shenyang 110819, \\ China \\ ${ }^{2}$ Shandong Gold Group Co. Ltd., Jinan 250000, China \\ ${ }^{3}$ Shenyang Ecological Environment Monitoring Center of Liaoning Province, Shenyang 110819, China \\ Correspondence should be addressed to Zhenbang Guo; wcpp2019@163.com
}

Received 5 December 2020; Revised 27 December 2020; Accepted 5 January 2021; Published 18 January 2021

Academic Editor: Erol Yilmaz

Copyright (c) 2021 Zhonghui Zhang et al. This is an open access article distributed under the Creative Commons Attribution License, which permits unrestricted use, distribution, and reproduction in any medium, provided the original work is properly cited.

\begin{abstract}
The use of blast furnace slag-based binders in cemented paste backfill (CPB) has become increasingly popular in China, due to its low cost and superior early-age strength. Increasing the solid content can increase the strength of CPB, but it will lead to a decrease in its fluidity. As a chemical admixture that can improve CPB slurry fluidity, superplasticizer is gaining increased interest in the field of $\mathrm{CPB}$. In this study, the effects of superplasticizer types and dosages, curing time, solid content, and binder content on the rheological properties of fresh $\mathrm{CPB}$ made of blast furnace slag-based binder (Slag-CPB) were studied. For Slag-CPB samples, polycarboxylate (PC) has the best water-reducing effect, followed by polymelamine sulfonate (PMS) and polynaphthalene sulfonate (PNS). In the absence of a superplasticizer, the shear yield stress and plastic viscosity of Slag-CPB are lower than those of $\mathrm{CPB}$ made of ordinary Portland cement (OPC-CPB). The water-reducing effect of PC on OPC-CPBs samples is stronger than that of Slag-CPB samples. The degradation rate of the water-reducing effect in slag-based samples is higher than that in cement-based samples. The effect of PC is affected by solid content and binder content. These results will contribute to a better understanding of the rheological behavior of Slag-CPB with superplasticizer.
\end{abstract}

\section{Introduction}

Mining activities not only obtain mineral resources, but also produce a lot of solid wastes (e.g., tailings) and underground voids [1-5]. The continuous improvement of national environmental protection requirements has prompted mining enterprises to seek scientific and efficient methods for underground voids and tailings management [6]. One of these emerging techniques is cemented paste backfill (CPB) which offers better technical and economic advantages over other filling methods like rock/slurry fills. The cemented paste backfill (CPB) is a composite material prepared by mixing a certain mass ratio of tailing, binders (e.g., cement, fly ash, or slag), and water [7-12]. It offers a range of advantages including efficient disposal of processing tailings, improved working environment, increased resource recovery, and improved ground controls [13-18].

The CPB should reach certain mechanical stability to resist external dynamic and static loads. Increasing the slurry concentration is one of the most effective ways to improve the mechanical stability of $\mathrm{CPB}$ and to reduce the filling cost [19]. However, an increase in slurry concentration will inevitably lead to a decrease in its fluidity. When the slurry concentration exceeds a certain critical value, the shear yield stress and dynamic viscosity can increase exponentially with the concentration, which will easily lead to pipe clogging, which can have significant financial ramifications [20]. Therefore, it is of crucial importance to improve the fluidity of $\mathrm{CPB}$ slurry as much as possible without reducing the solid content of slurry. As a chemical admixture that can reduce the water consumption while maintaining the slump of 
slurry basically unchanged, the superplasticizer provides a technical solution for the fluidity problem of high concentration CPB slurry $[13,14]$.

At present, there have been many studies on the effect of the superplasticizer on the fluidity of CPB slurry. For example, Haruna and Fall [21] studied the influence of the superplasticizer on the rheological properties of CPB at different curing temperatures. The results showed that the increase of curing temperature leads to the increase of yield stress and viscosity of fresh $\mathrm{CPB}$ slurry incorporating superplasticizer. Panchal et al. [22] evaluated the influence of different superplasticizer contents on the rheological properties of CPB. They indicated that the superplasticizer has an important influence on the rheological properties of $\mathrm{CPB}$, and it can be appropriately used to improve the fluidity of the $\mathrm{CPB}$ containing carbonate-rich process tailings. To study the effects of different superplasticizer types on strength and rheological behavior of $\mathrm{CPB}$, Mangane et al. [23] mixed four types of superplasticizers (lignosulfonate, naphthalene, melamine, and polycarboxylate) with $\mathrm{CPB}$ slurry containing various binder dosages. They found that polycarboxylate-based superplasticizer showed the best performance; it can reduce the dosage of binder and maintain the strength of $\mathrm{CPB}$ at the same time.

However, to our knowledge, most of the previous studies focus on CPB made of ordinary Portland cement (OPC$\mathrm{CPB}$ ). There are no studies addressing the effects of the superplasticizer on rheological properties of $\mathrm{CPB}$ made of blast furnace slag-based binder (Slag-CPB). As is known to all, the water-binding (or consuming) capacity of cement hydration is weak (a water-cement ratio of $0.2-0.25$ is adequate for cement hydration), and a typical water-cement ratio for CPB is 3-8. As a result, CPB made of OPC has a slow hardening rate, leading to a low strength (especially early strength). Moreover, the cost accounts for $75 \%$ of the total backfill cost with cement as a sole binder for CPB [24]. In recent years, blast furnace slag-based binders have been rapidly promoted and applied in many mines in China due to their high strength and low price. Therefore, the research on the influence of superplasticizer on the fluidity of slagbased CPB slurry is particularly important for the preparation, transportation, and structural optimization design of slag-based filling materials.

In view of this, this study aims to evaluate the rheological properties of Slag-CPB containing superplasticizer, with a special emphasis on quantifying the effect of superplasticizer type and dosage, curing time, solid content, and binder content on rheological parameters, principally yield stress, and plastic viscosity.

\section{Materials and Methods}

\subsection{Materials}

2.1.1. Tailings. The tailings used in the tests were unclassified tailings of a gold mine in Shandong province, China. The particle size distribution of tailings was determined by Malvern Laser Mastersizer 2000 and the results are shown in Figure 1 and Table 1 . The volume proportion of $-20 \mu \mathrm{m}$ particles in the tailings is $42.9 \%$, which can be classified as medium tailings [25]. The coefficient of curvature and coefficient of uniformity are 0.50 and 25.75 , respectively. X-ray fluorescence (XRF) results showed that the main chemical components of tailings were $\mathrm{SiO}_{2}(62.5 \%), \mathrm{Al}_{2} \mathrm{O}_{3}(16.2 \%)$, $\mathrm{K}_{2} \mathrm{O}(8.11 \%), \mathrm{Na}_{2} \mathrm{O}(3.07 \%)$, and $\mathrm{CaO}(2.98 \%)$, and some trace ingredients were also found. X-ray diffraction (XRD) test results showed that the tailing is mainly composed of quartz, albite, and mica (Figure 2).

2.1.2. Binders. The binder agents used in this study were a commercial OPC (viz., PO 42.5R, used as a reference) and a slag-based binder. The slag-based binder material consists of slag (70\%) and compound activator (30\%). The main components of the compound activator are a sulphate, a silicate, and an alkali metal salt. The particle size distribution of the slag was determined by Malvern Laser Mastersizer 2000 (Figure 1). Fine particles $(-20 \mu \mathrm{m})$ content in the slag accounted for $70.1 \%$, and the coefficients of curvature and coefficient of uniformity are 1.10 and 3.38, respectively. XRF analysis was used to determine the main chemical components of the slag, and the results showed that the slag mainly contained $\mathrm{CaO}$ (40.01 wt.\%), $\mathrm{SiO}_{2}$ (33.8 wt.\%), $\mathrm{Al}_{2} \mathrm{O}_{3}$ (15.71 wt.\%), and $\mathrm{MgO}$ (6.90 wt.\%) and some trace chemical components (Table 1). The XRD analysis of Slag shows a diffuse diffraction pattern typical of an amorphous glassy material, as shown in Figure 3. The basicity coefficient $\left(K_{\mathrm{b}}=(\mathrm{CaO}+\mathrm{MgO}) /\left(\mathrm{SiO}_{2}+\mathrm{Al}_{2} \mathrm{O}_{3}\right)\right)$ of slag is 0.95 and hence can be classified to be acid slag. The slag has an activity coefficient $\left.\left(\mathrm{HM}=\mathrm{CaO}+\mathrm{MgO}+\mathrm{Al}_{2} \mathrm{O}_{3}\right) / \mathrm{SiO}_{2}\right)$ of 1.85 .

2.1.3. Superplasticizer and Water. Three types of superplasticizers were used in this experiment: a polynaphthalene sulfonate (PNS), a polymelamine sulfonate (PMS), and a polycarboxylate (PC), all in powder form and purchased from BASF (Figure 4). Tap water with a $\mathrm{pH}$ of 7.5 was used as mixing water to achieve the desired consistency of the slurry [26]. The water mainly contains $\mathrm{Ca}(45.33 \mathrm{ppm}), \mathrm{Na}$ (4.62 ppm), and $\mathrm{Mg}$ (2.74 ppm) [27].

2.2. Mix Proportions. This experiment is divided into two stages. Stage I: three different types of superplasticizers were tested for water reduction effects under different dosages, and the best type of superplasticizer was selected. Stage II: based on the optimal type of superplasticizer, the effects of curing age, solid content, and binder content on water-reducing effect were studied. The solid content is the ratio of solids (tailing and binder) to total mass. The binder content is the mass ratio between binder and solids. The superplasticizer dosage is the ratio of the mass of the superplasticizer to the total mass of solids. The details of the $\mathrm{CPB}$ mixtures are summarized in Table 2.

2.3. Sample Preparation and Rheological Test. The CPB samples with different superplasticizer types and dosages, curing time, solid content, and binder content were prepared using a double spiral mixer. Before mechanical mixing, the 


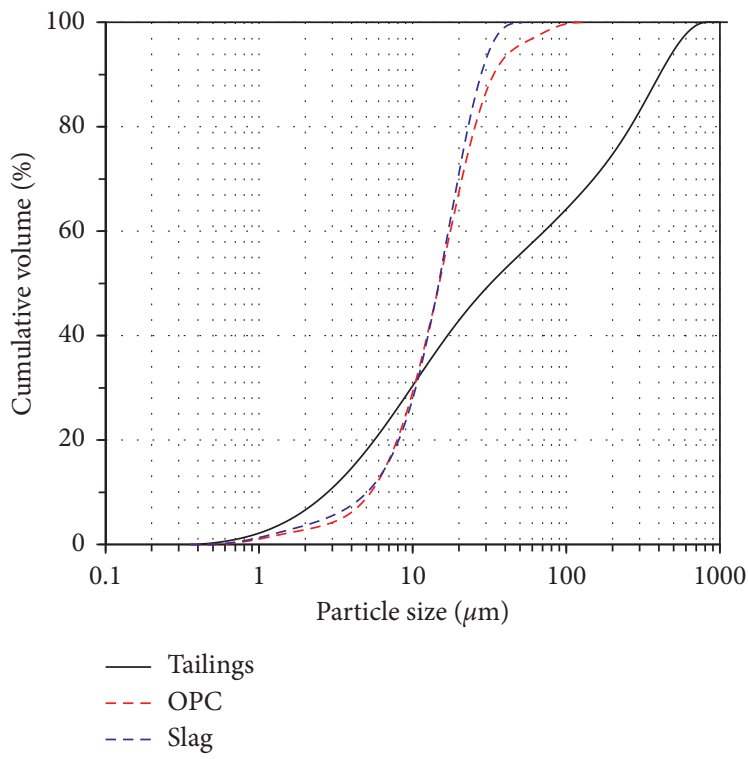

Figure 1: Particle size distribution curves for tailings, OPC, and slag.

TABLE 1: Main physical and chemical properties of tailings, OPC, and slag.

\begin{tabular}{|c|c|c|c|c|c|c|c|}
\hline Chemical composition (wt.\%) & Tailings & OPC & Slag & Physical properties & Tailings & OPC & Slag \\
\hline $\mathrm{CaO}$ & 2.98 & 62.34 & 40.01 & Specific gravity & 2.68 & 3.3 & 2.90 \\
\hline $\mathrm{Fe}_{2} \mathrm{O}_{3}$ & 1.72 & 5.06 & 0.38 & Specific surface $\left(\mathrm{cm}^{2} / \mathrm{g}\right)$ & 3470 & 5808 & 6198 \\
\hline $\mathrm{SiO}_{2}$ & 62.5 & 21.43 & 33.80 & $-20 \mu \mathrm{m}$ content $(\%)$ & 42.9 & 66.3 & 70.1 \\
\hline $\mathrm{Al}_{2} \mathrm{O}_{3}$ & 16.2 & 4.25 & 15.71 & $C_{\mathrm{u}}$ & 25.75 & 3.29 & 3.38 \\
\hline $\mathrm{MgO}$ & 0.52 & 2.61 & 6.90 & $C_{\mathrm{c}}$ & 0.50 & 1.25 & 1.10 \\
\hline $\mathrm{Na}_{2} \mathrm{O}$ & 3.07 & 0.41 & 0.05 & \multicolumn{4}{|c|}{ Pozzolanic strength index (\%) } \\
\hline $\mathrm{K}_{2} \mathrm{O}$ & 8.11 & 0.73 & 0.44 & 7 days & N/A & N/A & 69.6 \\
\hline $\mathrm{SO}_{3}$ & 0.45 & 1.48 & 0.18 & 28 days & $\mathrm{N} / \mathrm{A}$ & N/A & 90.4 \\
\hline
\end{tabular}

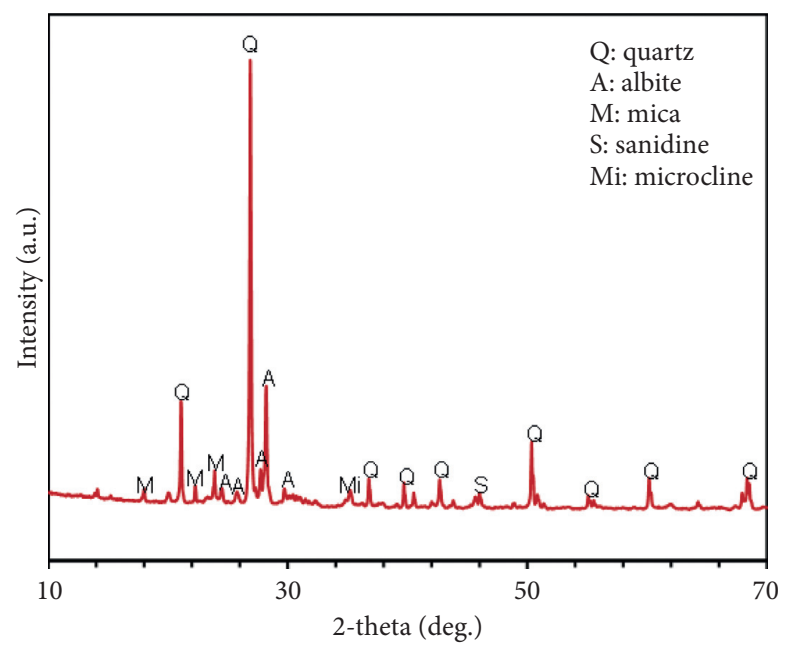

FIGURE 2: XRD pattern of tailings.

preweighed tailings, binder, and superplasticizer were homogenized by hand. Then, the required water was added to the solids, followed by 2 minutes of slow stirring and 2 minutes of fast stirring (see Figures 5 and 6).

The Brookfield RSR-SST rheometer with a four-bladed vane (diameter of $20 \mathrm{~mm}$ and length of $40 \mathrm{~mm}$ ) was used for rheological tests. The rotor was first sheared in $60 \mathrm{~s}$ with a shear rate of $100 \mathrm{~s}^{-1}$, and then the shear rate was reduced to $0.001 \mathrm{~s}^{-1}$ within $60 \mathrm{~s}$. In this study, the upper and lower boundary of the cross plate, the side boundary distance, and the test container boundary distance are both larger than the size requirements specified in ASTM 


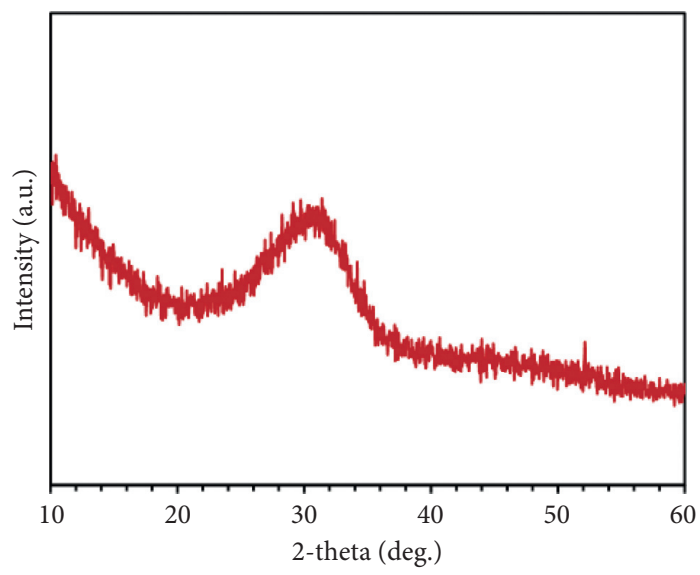

FIGURE 3: XRD pattern of slag material.
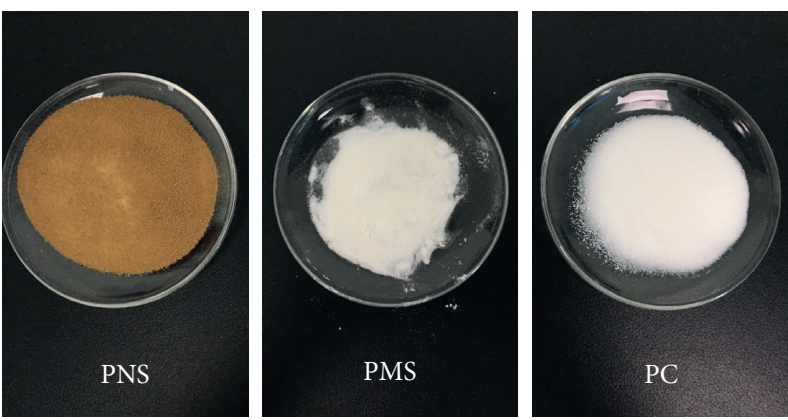

FIgURE 4: Three types of superplasticizers used in the test.

TABLE 2: Mix proportions of fresh CPB.

\begin{tabular}{|c|c|c|c|c|c|c|c|}
\hline Stage & Factors & $\begin{array}{l}\text { Superplasticizer } \\
\text { type }\end{array}$ & Binder type & $\begin{array}{l}\text { Superplasticizer } \\
\text { content }(\% 0)\end{array}$ & $\begin{array}{c}\text { Binder } \\
\text { content }(\%)\end{array}$ & $\begin{array}{c}\text { Solid } \\
\text { content }(\%)\end{array}$ & $\begin{array}{c}\text { Curing time } \\
(\mathrm{min})\end{array}$ \\
\hline \multirow{3}{*}{ I } & \multirow{3}{*}{$\begin{array}{l}\text { Types and dosage of } \\
\text { superplasticizer }\end{array}$} & PNS & $\begin{array}{l}\text { Slag-based } \\
\text { binder }\end{array}$ & $\begin{array}{c}0,0.36,0.73,1.09 \\
1.45,1.81\end{array}$ & 9.1 & 76 & 0 \\
\hline & & PMS & $\begin{array}{l}\text { Slag-based } \\
\text { binder }\end{array}$ & $\begin{array}{c}0,0.36,0.73,1.09 \\
1.45,1.81\end{array}$ & 9.1 & 76 & 0 \\
\hline & & PC & $\begin{array}{l}\text { Slag-based } \\
\text { binder }\end{array}$ & $0,0.36,0.54,1.09$ & 9.1 & 76 & 0 \\
\hline \multirow{11}{*}{ II } & \multirow{4}{*}{ Curing time } & PC & $\begin{array}{c}\text { Slag-based } \\
\text { binder, OPC }\end{array}$ & $0,0.36,0.54$ & 9.1 & 76 & 0 \\
\hline & & PC & $\begin{array}{c}\text { Slag-based } \\
\text { binder, OPC }\end{array}$ & $0,0.36,0.54$ & 9.1 & 76 & 30 \\
\hline & & PC & $\begin{array}{c}\text { Slag-based } \\
\text { binder, OPC }\end{array}$ & $0,0.36,0.54$ & 9.1 & 76 & 60 \\
\hline & & PC & $\begin{array}{c}\text { Slag-based } \\
\text { binder, OPC }\end{array}$ & $0,0.36,0.54$ & 9.1 & 76 & 120 \\
\hline & \multirow{3}{*}{ Solid content } & PC & $\begin{array}{l}\text { Slag-based } \\
\text { binder }\end{array}$ & $0,0.36,0.54$ & 9.1 & 76 & 0 \\
\hline & & PC & $\begin{array}{l}\text { Slag-based } \\
\text { binder }\end{array}$ & $0,0.36,0.54$ & 9.1 & 77 & 0 \\
\hline & & PC & $\begin{array}{l}\text { Slag-based } \\
\text { binder }\end{array}$ & $0,0.36,0.54$ & 9.1 & 78 & 0 \\
\hline & \multirow{4}{*}{ Binder content } & PC & $\begin{array}{l}\text { Slag-based } \\
\text { binder }\end{array}$ & $0,0.36,0.54$ & 4.8 & 76 & 0 \\
\hline & & PC & $\begin{array}{l}\text { Slag-based } \\
\text { binder }\end{array}$ & $0,0.36,0.54$ & 9.1 & 76 & 0 \\
\hline & & $\mathrm{PC}$ & $\begin{array}{l}\text { Slag-based } \\
\text { binder }\end{array}$ & $0,0.36,0.54$ & 14.3 & 76 & 0 \\
\hline & & PC & $\begin{array}{l}\text { Slag-based } \\
\text { binder }\end{array}$ & $0,0.36,0.54$ & 20.0 & 76 & 0 \\
\hline
\end{tabular}




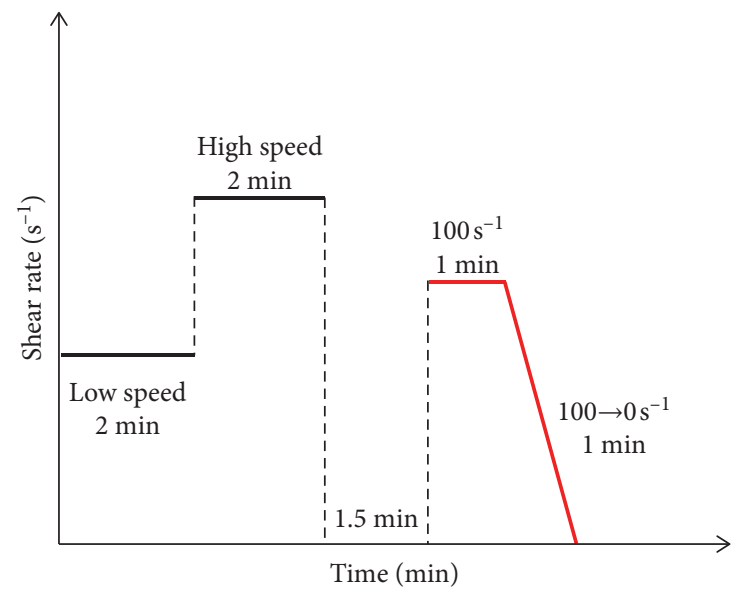

FIGURE 5: Flow chart of the mixing and rheological measurement sequence.

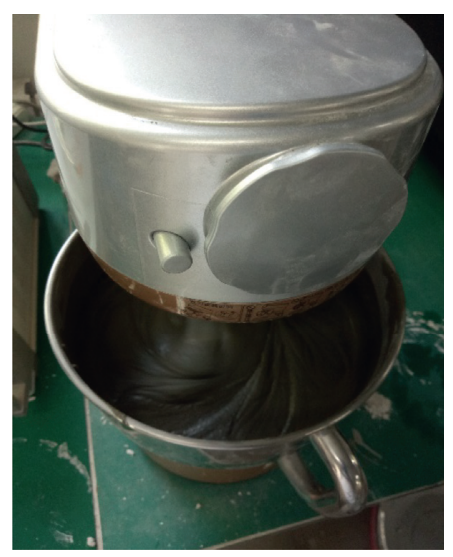

(a)

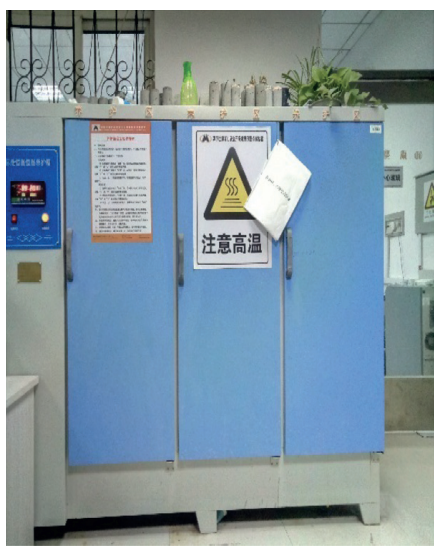

(b)

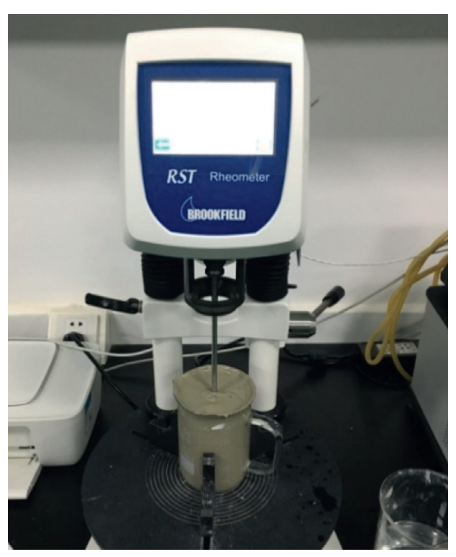

(c)

FIgURE 6: The preparation stages of CPB samples: (a) mixing, (b) curing, and (c) testing.

D4648/D4648M-16. Therefore, the boundary effect can be ignored. Each set of experiments were repeated at least 3 times to ensure the repeatability and accuracy of the results.

The Bingham model was used to fit the shear stress-shear rate data of the descending section $\left(100 \mathrm{~s}^{-1} \longrightarrow 0.0001 \mathrm{~s}^{-1}\right)$, so as to obtain the rheological parameters (yield shear stress and plastic viscosity) of the slurry. It should be noted that the model fitting correlation coefficients $R^{2}$ obtained in this experiment were all higher than 0.98 :

$$
\tau=\tau_{0}+\eta \cdot \gamma,
$$

where $\tau$ is the shear stress $(\mathrm{Pa}) ; \tau_{0}$ is shear yield stress $(\mathrm{Pa}) ; \eta$ is the plastic viscosity (Pa.s); and $\gamma$ is the shear rate $\left(\mathrm{s}^{-1}\right)$.

\section{Results and Discussion}

3.1. Effects of Types and Dosages of Superplasticizers. Figure 7 shows the influence of different superplasticizer types and dosages on the rheological parameters of Slag-CPBs at
0 min. It should be noted that the absence of rheological parameters of Slag-CPBs with $1.45 \%$ and $1.81 \%$ PC is due to serious bleeding. It can be seen from the figure that the type and dosage of superplasticizer have a significant influence on the rheological parameters of Slag-CPBs. Regardless of the type of superplasticizer, with the increase of superplasticizer dosage, the shear yield stress and plastic viscosity of the Slag$\mathrm{CPBs}$ decreases gradually; that is, the fluidity of slurry is gradually improved. A similar observation has also been obtained by previous studies (e.g., [28, 29]).

The results in Figure 7 also indicate that the type of the superplasticizer has a significant influence on the rheological properties of Slag-CPBs. One can observe that the PC is more efficient in improving the fluidity of Slag-CPBs, compared to the PMS and PNS. A similar observation was also made on CPB made of blended cement (80\% slag and 20\% Portland cement) by Ouattara et al. [30]. PC significantly reduces both yield stress and plastic viscosity of Slag-CPBs, and this positive effect increases approximately linearly with the PC dosage. At relatively low dosages, PNS shows a good improvement effect on the plastic viscosity of slurry, but when the dosage reaches 


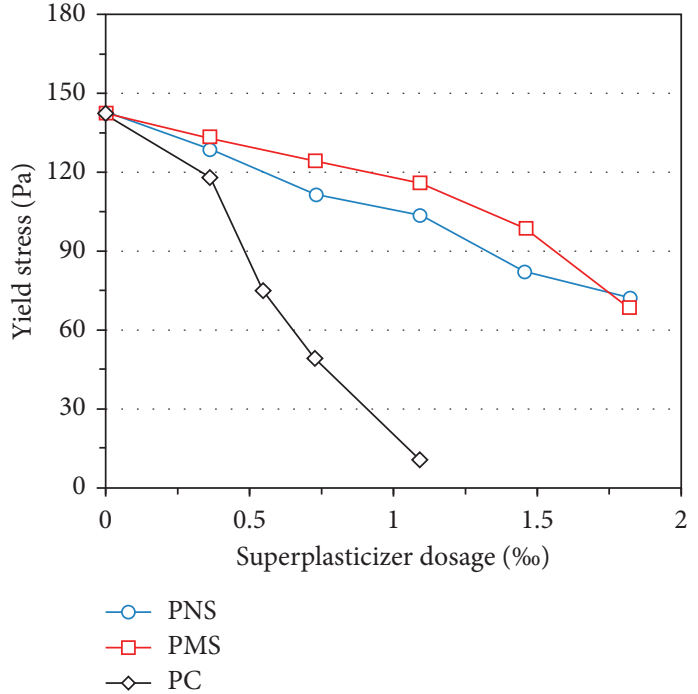

(a)

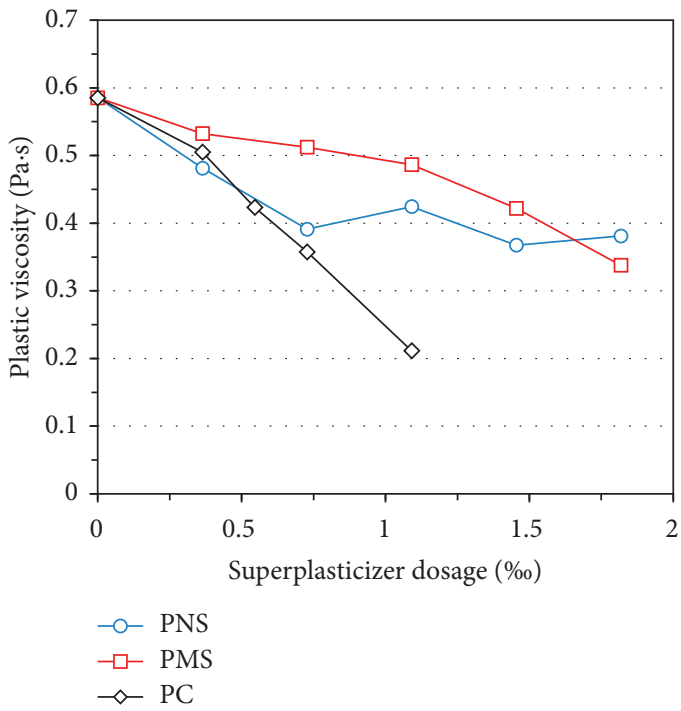

(b)

FIgURE 7: Effects of superplasticizer types and dosages on the development of (a) yield stress and (b) plastic viscosity of CPB.

$0.72 \%$, the water-reducing effect tends to be saturated. PMS has the worst water-reducing effect, and its water-reducing effect does not change significantly with the increase of dosage compared with PC and PNS. It can also be seen from Figure 7 that, with the increase of superplasticizer dosage, the difference of water-reducing effect between PC and other superplasticizers gradually increases. The saturated content of PC is much lower than that of PNS and PMS. In addition, by comparing Figures $7(\mathrm{a})$ and $7(\mathrm{~b})$, it can be seen that the influence degree of superplasticizer on yield stress is higher than that on plastic viscosity.

\subsection{Time-Dependent Evolution of Rheological Properties.}

Figure 8 shows the time-dependent evolution of the rheological properties of OPC and Slag-CPBs with different PC dosages. It is obvious that the yield stress and plastic viscosity of all samples increased with the increase of curing time regardless of PC dosage and binder type. This is mainly because with the increase of curing time, the amount of binder hydration products continues to increase $[31,32]$. In absence of the PC, both yield stress and plastic viscosity of OPC-CPB are higher than those of Slag-CPB. This is because the absolute Zeta potential of slag particles is higher than that of cement particles $[33,34]$. The binder type significantly affects the effect of $\mathrm{PC}$. The water-reducing effect of the PC on OPC-CPBs is stronger than that of Slag-CPBs. This observation is contrary to the results of the investigations conducted by Ouattara et al. [30], who concluded that the blended binder made of $80 \%$ Slag and 20\% OPC appeared to be more compatible with the PC compared to the OPC. Moreover, Adjoudj et al. [35] demonstrated that PC superplasticizer becomes more effective when Slag is incorporated. These difference in the effect of PC indicates that the compound activator used in the study significantly reduces the adsorption of PC to the Slag particles.

The results in Figure 8 also show that, regardless of the binder type, the rheological parameters of the sample containing PC grow at a higher rate over time than those of the sample without PC; that is, the effect of PC degrades over time. This is because with the continuous hydration of the binder, the hydration products generated will cover the absorbent PC on the surface of solid particles, thus resulting in the degradation of the effect of PC. Moreover, the degradation effect of the $\mathrm{PC}$ with time is more obvious in Slag-CPBs than that of OPC-CPBs.

3.3. Effect of Solid Content. The influence of PC on the rheological parameters of Slag-CPBs with different solid contents $(76 \%, 77 \%$, and $78 \%)$ is shown in Figure 9. The binder content of all samples is 9.1. As can be seen from Figure 9, with the solid content increasing from $76 \%$ to $77 \%$ and $78 \%$, the shear yield stress of CPB without PC increases from $142 \mathrm{~Pa}$ to $201 \mathrm{~Pa}$ and $247 \mathrm{~Pa}$, and the corresponding plastic viscosity increases from $0.59 \mathrm{~Pa} \cdot \mathrm{s}$ to $0.83 \mathrm{~Pa} \cdot \mathrm{s}$ and $1.17 \mathrm{~Pa} \cdot \mathrm{s}$. This indicates that only a slight increase in solid content can result in a significant increase in rheological parameters for high solid content CPB. This observation is consistent with the results of the investigations conducted by Ouattara et al. [36].

Figure 10 shows the percentage decrease of rheological parameters of Slag-CPB with different solid contents and PC dosages. It can be seen from the figure that the degree of improvement in yield stress with different solid contents depends on PC dosages. When the PC dosage is low $(0.36 \% 0)$, the effect of PC on shear yield stress increases with increasing solid content. However, when a high dosage PC (0.54\%o) is added, the water-reducing effect tends to weaken with increasing solid content. The results 


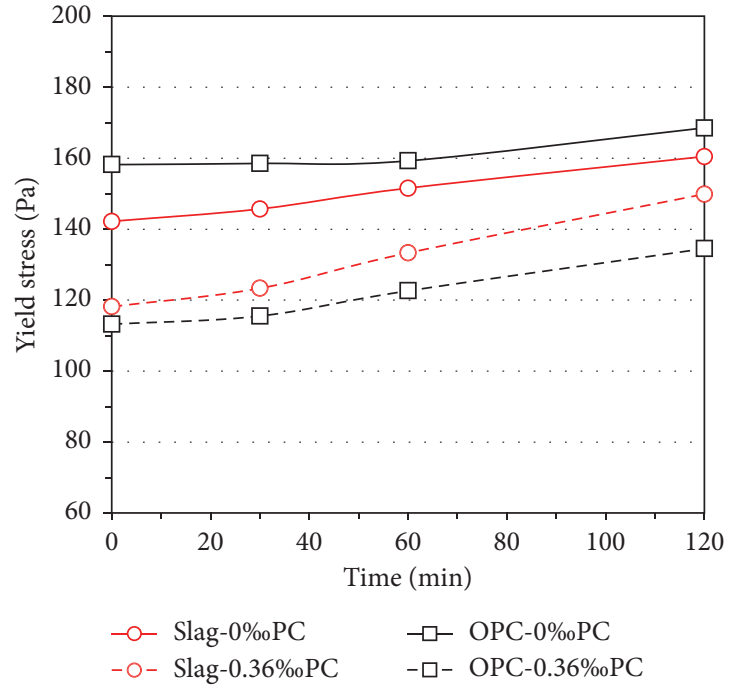

(a)

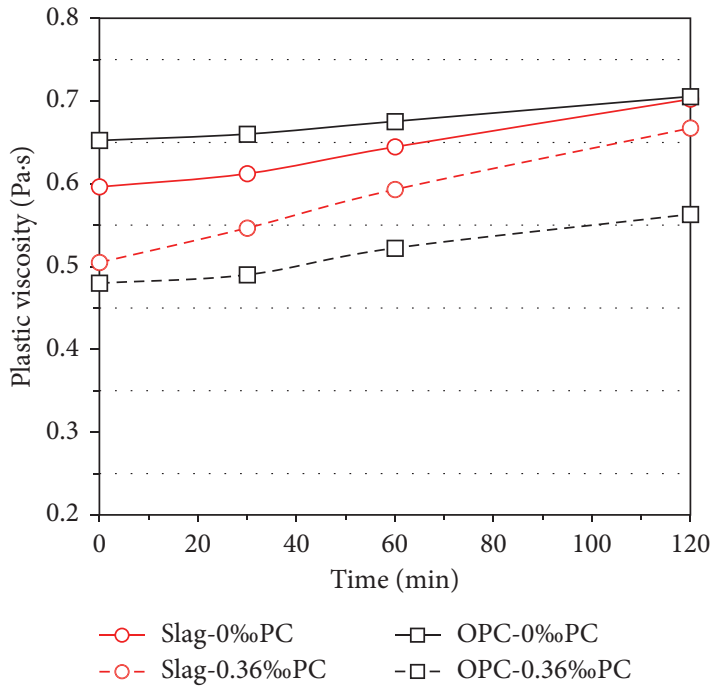

(b)

FIGURE 8: Time-dependent evolution of (a) yield stress and (b) plastic viscosity of CPB containing different binder types and PC dosages.

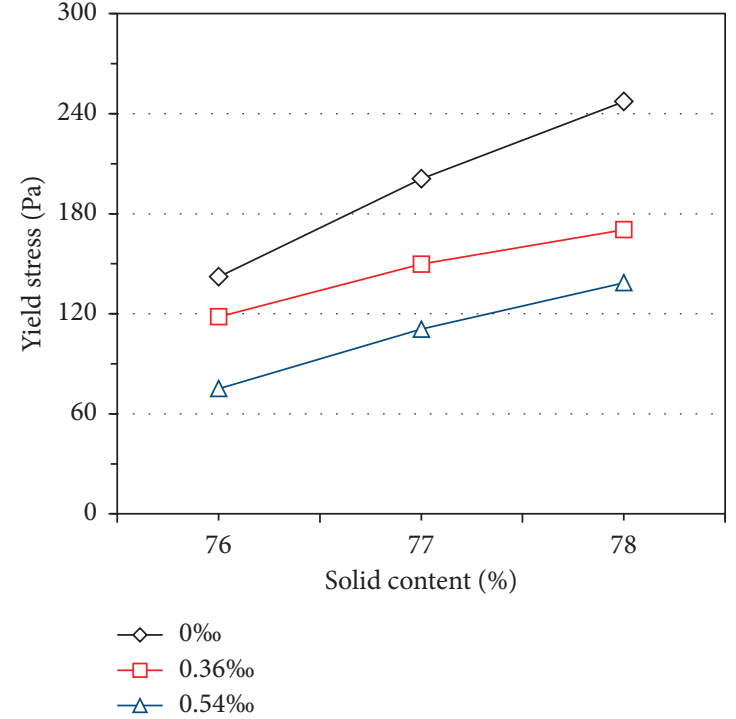

(a)

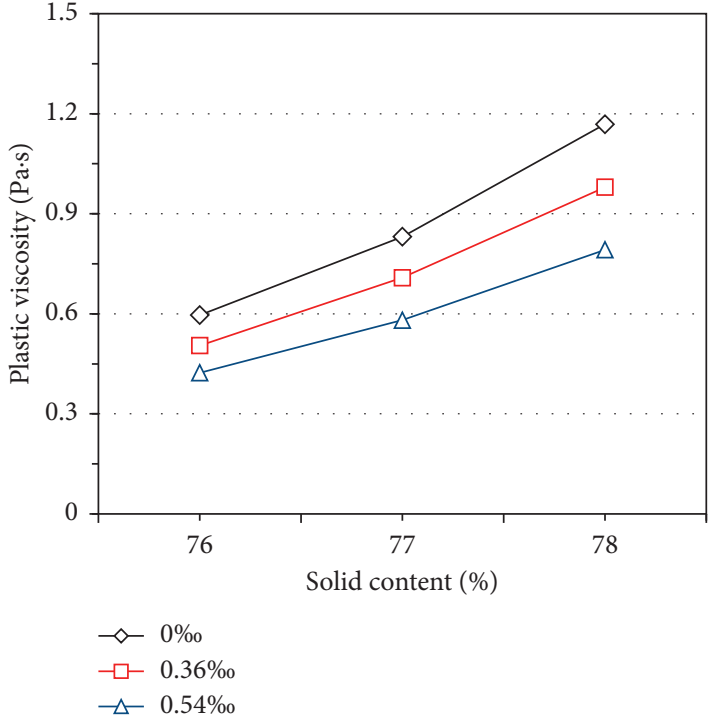

(b)

FIgURE 9: Effects of solid contents and PC dosages on the development of (a) yield stress and (b) plastic viscosity of CPB.

in Figure 10 also show that when the PC dosage is fixed, the degree of improvement in plastic viscosity of PC is positively correlated with the solid content. However, Yang et al. [19] reported that as the solids content increases, the cemented tailings backfill samples with a higher dosage of superplasticizer have a lower rate of decrease in fluidity. This difference in the effect of superplasticizer with increasing solid content can be attributed to the difference in the composition of binder and tailings.
3.4. Effects of Binder Content. The rheological parameters variation of fresh Slag-CPBs with different binder contents and PC dosages is shown in Figure 11. The results presented in Figure 11 show that the shear yield stress and plastic viscosity of the slurry without PC increase gradually with the increase of the binder content. Similar results have been observed by Sandeep et al. [22], Simon and Grabinsky [37], and Phan et al. [38]. However, the rate of the increase in rheological parameters decreases gradually with the PC dosage. Compared with the solid content, the binder content 


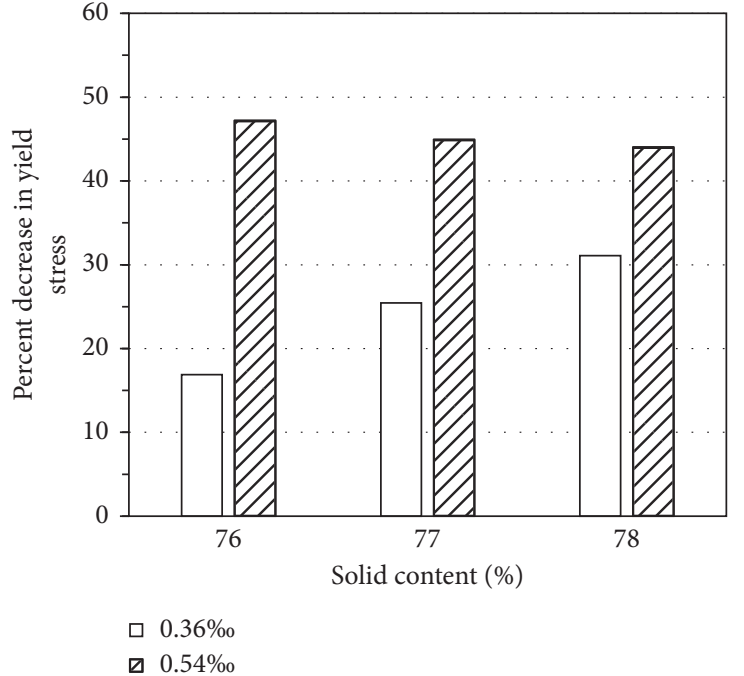

(a)

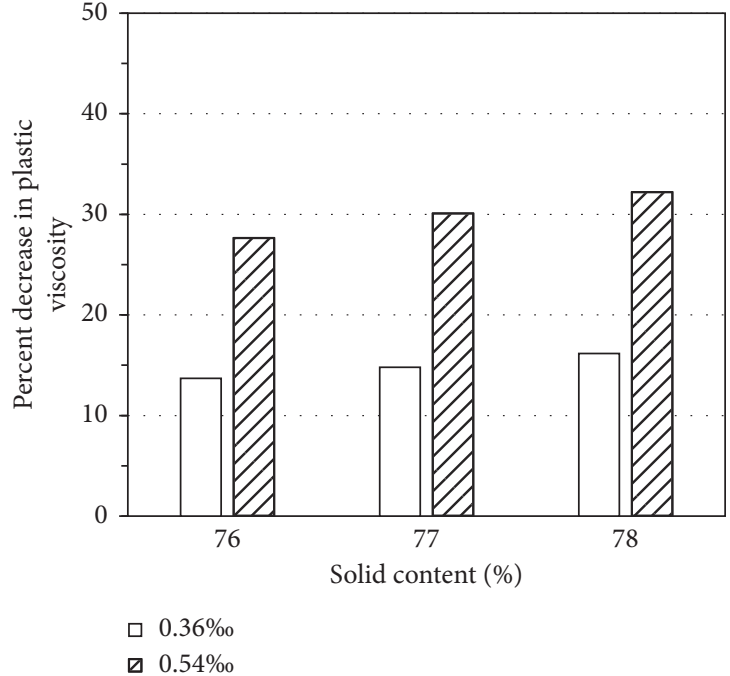

(b)

FIGURE 10: Effects of solid contents and PC dosages on the percentage reduction of (a) yield stress and (b) plastic viscosity of CPB.

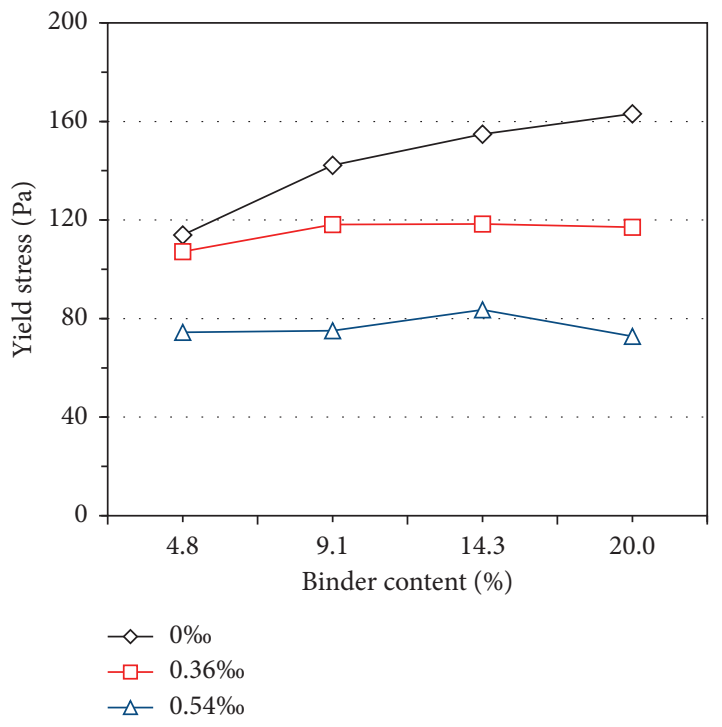

(a)

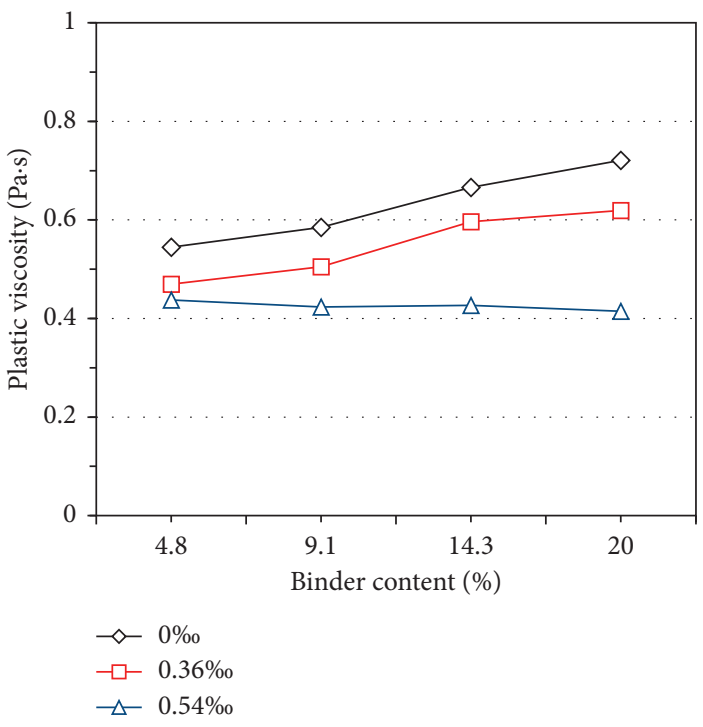

(b)

FIGURE 11: Effects of binder content and PC dosages on the development of (a) yield stress and (b) plastic viscosity of CPB.

has less influence on the rheological parameters (see Figures 9 and 11). When the PC dosage is low $(0.36 \% 0)$, the higher the water-to-cement ratio, the higher the yield stress and plastic viscosity of CPB samples. When the PC dosage is high $(0.54 \%)$, the yield stress and plastic viscosity of slurry with different solid contents are basically the same.

Figure 12 illustrates the influence of the PC dosages on the percentage reduction of rheological parameters. The results in Figure 12 show that when the PC dosage is low $(0.36 \%)$, the positive effect of PC on yield stress increases, while this effect on plastic viscosity decreases as the binder content increases. When the PC content is high $(0.54 \%)$, the improvement effect of PC on the yield stress basically does not change with the increase of the binder content, while the corresponding improvement effect of plastic viscosity is more significant. 


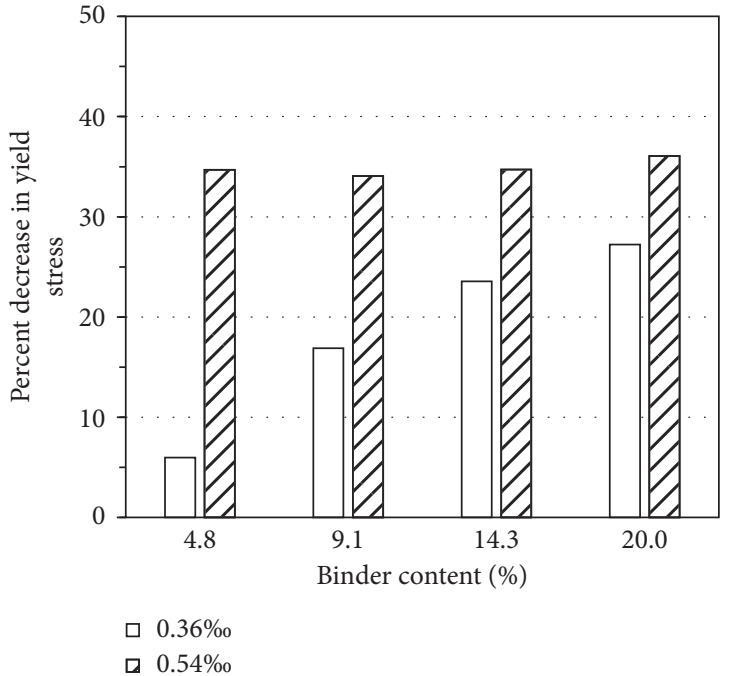

(a)

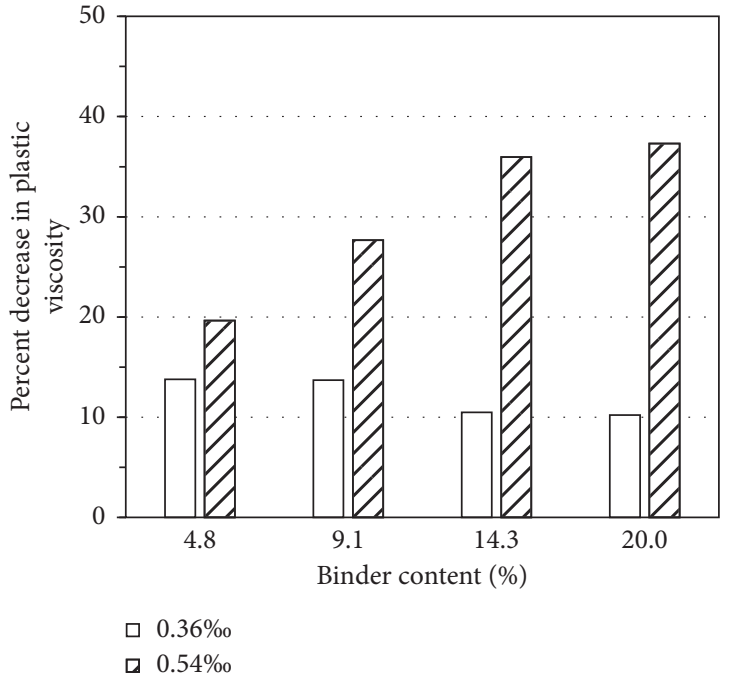

(b)

FIgURE 12: Effects of binder content and PC dosages on the percentage reduction of (a) yield stress and (b) plastic viscosity of CPB.

\section{Conclusions}

In this study, the rheological properties of the Slag-CPBs under different superplasticizer types and dosages were tested, and the influences of solid content and binder content were analysed. The following main conclusions can be drawn:

(1) Both yield stress and plastic viscosity of the Slag-CPBs decrease with increasing superplasticizer dosage; that is, the flow characteristic of slurry increases. Different superplasticizer types have significant differences in water-reducing effects. The PC has the best waterreducing effect, followed by the PMS and PNS.

(2) The yield stress and plastic viscosity of OPC-CPBs are higher than those of Slag-CPBs. The water-reducing effect of PC on OPC-CPBs is stronger than that of Slag-CPBs. The degradation rate of the water-reducing effect in Slag-CPBs is significantly higher than that in OPC-CPBs.

(3) The shear yield stress and plastic viscosity of the Slag-CPB without the addition of PC increase rapidly with the solid content. The degree of improvement of PC to the shear yield stress of slurry with different solid contents depends on PC dosage. When PC dosage is low $(0.36 \%)$, the higher the solid content is, the higher the shear yield stress and plastic viscosity are. When PC is added at a higher dosage $(0.54 \%)$, the shear yield stress improves more obviously with the increase of solid content, while the plastic viscosity improves less.

(4) The shear yield stress and plastic viscosity of Slag-CPBs without the addition of $\mathrm{PC}$ increase with the increase of the binder content. When the PC dosage is low $(0.36 \%)$, the improvement effect of PC on yield stress is better and the improvement effect of PC on plastic viscosity is worse as the binder content increases. When the PC dosage is high $(0.54 \%)$, the improvement effect of PC on the yield stress basically does not change with the increase of the binder content, while the corresponding improvement effect of plastic viscosity is more significant.

It is noteworthy that the binder in this paper contains only one mineral admixture. Therefore, in future work, we will study the coupling effect of ternary binder made of ordinary Portland cement, fly ash, and granulated blast furnace slag with a superplasticizer.

\section{Data Availability}

The data used to support the findings of this study are included within the article.

\section{Conflicts of Interest}

The authors declare that there are no conflicts of interest regarding the publication of this paper.

\section{Acknowledgments}

The authors would like to gratefully acknowledge the financial support from the State Key Research Development Program of China (2018YFC0604601) and the Revitalization Talent Program (XLYC1805008).

\section{References}

[1] D. I. Wang, Q.-I. Zhang, Q.-S. Chen, C.-C. Qi, Y. Feng, and C.-C. Xiao, "Temperature variation characteristics in flocculation settlement of tailings and its mechanism," International Journal of Minerals, Metallurgy and Materials, vol. 27, pp. 1438-1448, 2020.

[2] M. Fall, J. C. Célestin, M. Pokharel, and M. Touré, "A contribution to understanding the effects of curing temperature 
on the mechanical properties of mine cemented tailings backfill," Engineering Geology, vol. 114, no. 3-4, pp. 397-413, 2010.

[3] M. Benzaazoua, B. Bussière, I. Demers, M. Aubertin, É. Fried, and A. Blier, "Integrated mine tailings management by combining environmental desulphurization and cemented paste backfill: application to mine Doyon, Quebec, Canada," Minerals Engineering, vol. 21, no. 4, pp. 330-340, 2008.

[4] H. Jiang, H. Yi, E. Yilmaz, S. Liu, and J. Qiu, "Ultrasonic evaluation of strength properties of cemented paste backfill: effects of mineral admixture and curing temperature," $\mathrm{Ul}$ trasonics, vol. 100, Article ID 105983, 2020.

[5] J. Qiu, Z. Guo, L. Yang, H. Jiang, and Y. Zhao, "Effects of packing density and water film thickness on the fluidity behaviour of cemented paste backfill," Powder Technology, vol. 359, pp. 27-35, 2020.

[6] A. Tariq and E. K. Yanful, "A review of binders used in cemented paste tailings for underground and surface disposal practices," Journal of Environmental Management, vol. 131, pp. 138-149, 2013.

[7] M. Ozkaymak, S. Selimli, D. Kaya, and U. Uzun, "Searching the fertility potential of iron and steel industry blast furnace slag," World Journal of Engineering, vol. 13, no. 6, pp. 482-486, 2016.

[8] D. Dutta and S. Ghosh, "The role of delayed water curing in improving the mechanical and microstructural properties of alkali activated fly ash based geopolymer paste blended with slag," World Journal of Engineering, vol. 16, no. 1, pp. 103-114, 2019.

[9] S. Raj, A. K. Rai, and V. G. Havanagi, "Suitability of stabilized copper slag and fly ash mix for road construction," World Journal of Engineering, vol. 15, no. 3, pp. 336-344, 2018.

[10] M. Fall and M. Benzaazoua, "Modeling the effect of sulphate on strength development of paste backfill and binder mixture optimization," Cement and Concrete Research, vol. 35, no. 2, pp. 301-314, 2005.

[11] S. Ben Messaoud and B. Mezghiche, "Experimental analysis of behaviour of light weight high performance concrete with crystallized slag," World Journal of Engineering, vol. 13, no. 5, pp. 447-452, 2016.

[12] E. Yilmaz, M. Benzaazoua, T. Belem, and B. Bussière, "Effect of curing under pressure on compressive strength development of cemented paste backfill," Minerals Engineering, vol. 22, no. 9-10, pp. 772-785, 2009.

[13] K. Klein and D. Simon, "Effect of specimen composition on the strength development in cemented paste backfill," $\mathrm{Ca}$ nadian Geotechnical Journal, vol. 43, no. 3, pp. 310-324, 2006.

[14] A. Kesimal, E. Yilmaz, B. Ercikdi, I. Alp, and H. Deveci, "Effect of properties of tailings and binder on the short-and long-term strength and stability of cemented paste backfill," Materials Letters, vol. 59, no. 28, pp. 3703-3709, 2005.

[15] H. Jiang, Z. Qi, E. Yilmaz, J. Han, J. Qiu, and C. Dong, "Effectiveness of alkali-activated slag as alternative binder on workability and early age compressive strength of cemented paste backfills," Construction and Building Materials, vol. 218, pp. 689-700, 2019.

[16] B. Ercikdi, G. Külekci, and T. Yllmaz, "Utilization of granulated marble wastes and waste bricks as mineral admixture in cemented paste backfill of sulphide-rich tailings," Construction and Building Materials, vol. 93, pp. 573-583, 2015.

[17] S. Zhang, L. Yang, F. Ren, J. Qiu, and H. Ding, "Rheological and mechanical properties of cemented foam backfill: effect of mineral admixture type and dosage," Cement and Concrete Composites, vol. 112, Article ID 103689, 2020.
[18] L. Yang, W. Xu, E. Yilmaz, Q. Wang, and J. Qiu, “A combined experimental and numerical study on the triaxial and dynamic compression behavior of cemented tailings backfill," Engineering Structures, vol. 219, Article ID 110957, 2020.

[19] L. Yang, E. Yilmaz, J. Li, H. Liu, and H. Jiang, "Effect of superplasticizer type and dosage on fluidity and strength behavior of cemented tailings backfill with different solid contents," Construction and Building Materials, vol. 187, pp. 290-298, 2018.

[20] R. J. Jewell and A. B. Fourie, Paste and Thickened Tailings: A Guide, Australian Centre for Geomechanics, The University of Western Australia, Perth, Australia, 2006.

[21] S. Haruna and M. Fall, "Time-and temperature-dependent rheological properties of cemented paste backfill that contains superplasticizer," Powder Technology, vol. 360, pp. 731-740, 2020.

[22] S. Panchal, D. Deb, and T. Sreenivas, "Variability in rheology of cemented paste backfill with hydration age, binder and superplasticizer dosages," Advanced Powder Technology, vol. 29, no. 9, pp. 2211-2220, 2018.

[23] M. B. C. Mangane, R. Argane, R. Trauchessec, A. Lecomte, and M. Benzaazoua, "Influence of superplasticizers on mechanical properties and workability of cemented paste backfill," Minerals Engineering, vol. 116, pp. 3-14, 2018.

[24] F. Hassani, S. M. Razavi, and I. Isagon, "A study of physical and mechanical behaviour of gelfill," CIM Bulletin, vol. 2, no. 5, pp. 1-7, 2007.

[25] M. Fall, T. Belem, S. Samb, and M. Benzaazoua, "Experimental characterization of the stress-strain behaviour of cemented paste backfill in compression," Journal of Materials Science, vol. 42, no. 11, pp. 3914-3922, 2007.

[26] S. Bechar and D. Zerrouki, "Effect of natural pozzolan on the fresh and hardened cement slurry properties for cementing oil well," World Journal of Engineering, vol. 15, no. 4, pp. 513-519, 2018.

[27] Z. Guo, J. Qiu, H. Jiang, J. Xing, X. Sun, and Z. Ma, "Flowability of ultrafine-tailings cemented paste backfill incorporating superplasticizer: insight from water film thickness theory," Powder Technology, vol. 381, pp. 509-517, 2021.

[28] L. Huynh, D. A. Beattie, D. Fornasiero, and J. Ralston, "Effect of polyphosphate and naphthalene sulfonate formaldehyde condensate on the rheological properties of dewatered tailings and cemented paste backfill," Minerals Engineering, vol. 19, no. 1, pp. 28-36, 2006.

[29] B. Ercikdi, F. Cihangir, A. Kesimal, H. Deveci, and İ. Alp, "Utilization of water-reducing admixtures in cemented paste backfill of sulphide-rich mill tailings," Journal of Hazardous Materials, vol. 179, no. 1-3, pp. 940-946, 2010.

[30] D. Ouattara, M. Mbonimpa, A. Yahia, and T. Belem, "Assessment of rheological parameters of high density cemented paste backfill mixtures incorporating superplasticizers," Construction and Building Materials, vol. 190, pp. 294-307, 2018.

[31] H. Jiang and M. Fall, "Yield stress and strength of saline cemented tailings in sub-zero environments: Portland cement paste backfill," International Journal of Mineral Processing, vol. 160, pp. 68-75, 2017.

[32] D. Wu, M. Fall, and S. J. Cai, "Coupling temperature, cement hydration and rheological behaviour of fresh cemented paste backfill," Minerals Engineering, vol. 42, pp. 76-87, 2013.

[33] J. Haiqiang, M. Fall, and L. Cui, "Yield stress of cemented paste backfill in sub-zero environments: experimental results," Minerals Engineering, vol. 92, pp. 141-150, 2016. 
[34] H. Jiang, M. Fall, E. Yilmaz, Y. Li, and L. Yang, "Effect of mineral admixtures on flow properties of fresh cemented paste backfill: assessment of time dependency and thixotropy," Powder Technology, vol. 372, pp. 258-266, 2020.

[35] M. h. Adjoudj, K. Ezziane, E. H. Kadri, T.-T. Ngo, and A. Kaci, "Evaluation of rheological parameters of mortar containing various amounts of mineral addition with polycarboxylate superplasticizer," Construction and Building Materials, vol. 70, pp. 549-559, 2014.

[36] D. Ouattara, A. Yahia, M. Mbonimpa, and T. Belem, "Effects of superplasticizer on rheological properties of cemented paste backfills," International Journal of Mineral Processing, vol. 161, pp. 28-40, 2017.

[37] D. Simon and M. Grabinsky, "Apparent yield stress measurement in cemented paste backfill," International Journal of Mining, Reclamation and Environment, vol. 27, no. 4, pp. 231-256, 2013.

[38] T. H. Phan, M. Chaouche, and M. Moranville, "Influence of organic admixtures on the rheological behaviour of cement pastes," Cement and Concrete Research, vol. 36, no. 10, pp. 1807-1813, 2006. 